\title{
PERFORMANCE EVALUATION OF A COMPOSITE-PADDED EVAPORATIVE COOLING STORAGE BIN
}

\author{
N. J. Ogbuagu1 ${ }^{1}$, I. A. Green ${ }^{2}$, C. N. Anyanwu ${ }^{3,}{ }^{*}$ and J. I. Ume ${ }^{4}$ \\ 1,2 Department of Agric. Engineering, Enugu State Univ. of SCience and TeChnology, Enugu State. Nigeria \\ 3 NATIONAl CENTRE FOR ENERGY RESEARCH \& DEVELOPMENT, UNIVERSITY OF NigERIA NSUKKA, ENUGU STATE. NIGERIA \\ 4DEPARTMENT OF MEChANICAL ENGINEERING, UNIVERSITY OF NigERIA NSUKKA, ENUGU STATE. NIGERIA \\ E-mail addresses. ${ }^{1}$ njogbuagu@yahoo.com, ${ }^{2}$ giwarifa@yahoo.com, ${ }^{3}$ cosmas.anyanwu@unn.edu.ng, \\ 4 joshua.ume@unn.edu.ng
}

\begin{abstract}
In tropical regions, postharvest losses of fruits and vegetables induced by high temperatures is a major challenge to agriculture, especially in places with poor or no electric power supply. The present study is on the comparative performance evaluation of a $92 \mathrm{~kg}$ capacity storage bin for the preservation of fruits and vegetables, operating on the principle of evaporative cooling. A 24V DC, $0.37 \mathrm{~kW}$ fan attached to the back of the cooler serves to blow in cooling air. The average temperature drop and saturation efficiency in the evaporative cooler during the no-load test were $5^{\circ} \mathrm{C}$ and $42 \%$, respectively. The facility was able to sustain tomatoes, garden eggs and carrots stored in it for ten days. The weight losses at ambient temperature were found to be 70\%, 30\%and 45\% for tomatoes, garden eggs and carrots, respectively; while those stored at cooler temperature were $10 \%, 25 \%$, and $40 \%$ for tomatoes, garden eggs and carrots respectively. The evaporative cooler performed best for storage of tomatoes.
\end{abstract}

Keywords: Evaporative cooling, vegetables, storage, fruits, agriculture, temperature.

\section{INTRODUCTION}

Vegetables and fruits are very important food items that are widely consumed in many parts of the world. They form an essential part of a balanced diet. Fruits and vegetables are important sources of digestible carbohydrates, minerals and vitamins $\mathrm{A}$ and $\mathrm{C}$. In addition, they provide roughage (indigestible carbohydrates), which is needed for normal healthy digestion [1]. UNIDO [2] estimated that between 1979 and 1980, food processing industries accounted for more than one fifth of all manufacturing industries in developing countries and a substantial part of the raw materials were sourced from fruits and vegetables which are processed into other forms. These products consist mainly of water; hence without adequate storage after harvest, they shrivel, wither or rot away rapidly, particularly under hot tropical conditions due to loss of moisture, change in composition and pathological attack [3-4]. In order to maintain freshness in these products, they have to be stored in low temperature and high relative humidity [5-7]. Adequate storage prolongs usefulness, checks market gluts, provides a wider selection of fruits and vegetables throughout the year.
Some methods of preservation of raw and processed fruits and vegetables have been adopted. Amongst these, refrigeration is very popular but it has been observed that several tropical fruits and vegetables, e.g. banana, plantain and mango cannot be stored in domestic refrigerator for a long period of time as they are susceptible to chilling injury [8]. In addition, the costs of refrigerators are beyond the reach of low income farmers in rural communities.

Evaporative cooling is a system that utilizes heat to evaporate the water, resulting in a drop in the air temperature and increase in relative humidity. FAO [9] had advocated the use of evaporative cooling for the storage of fruits and vegetables. The efficiency of an active evaporative cooler depends on the rate and amount of evaporation of water from the pad; which is dependent on the air velocity through the pad, pad thickness and the degree of saturation of the pad. The degree of saturation of the pad is a function of the water flow rate wetting the pad and the construction material of the pad [10-11]. Previous studies on evaporative cooling had shown that different materials and methods were used. Evaporative cooler developed by Abdalla and Abdalla [12] successfully used palm leaves as pad 
material.Sushmita et al. [13]also carried out a research on evaporative cooling and found out that weight loss of fruits and vegetables kept inside the chamber was lower than those stored outside the chamber. Olosunde [14] also conducted an evaluation of absorbent materials and the result showed that jute material had the overall advantage over other materials used in the analysis. Mordi and Olorunda [15] in their study on storage of tomatoes in evaporative cooler environment reported a drop of $8.2^{\circ} \mathrm{C}$ from ambient condition of $33^{\circ} \mathrm{C}$ while the relative humidity increased by $36.6 \%$. Helmy et al. in their study on application of evaporative cooler to greenhouse storage[16] also revealed that there was an average temperature drop of $7.5{ }^{\circ} \mathrm{C}$ and $15 \%$ increase in relative humidity. Similar result was presented by Mogaji and Fapetu [17].

The aim of this study is to develop a simple and afforadable evaporative cooler for storage of fresh fruits and vegetables and investigate its performance in the storage of three common vegetable crops.

\section{MATERIALS AND METHODS}

\subsection{Location of the Research Work}

The research work was carried out in the department of Agricultural Engineering, Enugu State University of Science and Technology.

\subsection{Design Considerations}

The main design considerations were the sepcific volume of the crops to be stored, the thermal and mechanical properties of the materials of construction, as well as the power required to pump cooling water at the desired speed through the pad materials.

\subsection{Design Calculations}

\subsubsection{Total Heat Loss}

Removal of excessive heat from a structure requires using evaporative cooling pads and mechanical ventilation [18] as shown in figure 1. Thermal conductivities $(\mathrm{K})$ and thickness of the materials are given in Table 1 . Heat loss per unit area through the insulating material was calculated using:

$$
\begin{aligned}
Q_{l} & =\frac{K \Delta T}{X} \\
& =\frac{\Delta T}{\sum R} \\
\sum R & =R_{o}+R_{j o}+R_{c}+R_{j i}+R_{i}
\end{aligned}
$$

In (1), (2) and (3), $Q_{l}$ is the Heat loss per unit area of the structure (Watts), $\mathrm{K}$ is the Thermal conductivity of material $(\mathrm{W} / \mathrm{mK}), \Delta T$ is the Temperature change $\left({ }^{\circ} \mathrm{C}\right), \mathrm{X}$ is the Thickness of material (m) and $R_{o, j o, c, j i, i}$ is the Thermal resistance of outside air, outer jutebag, charcoal, inner jute and inside air $\left(\mathrm{m}^{2} \mathrm{~K} / \mathrm{W}\right)$

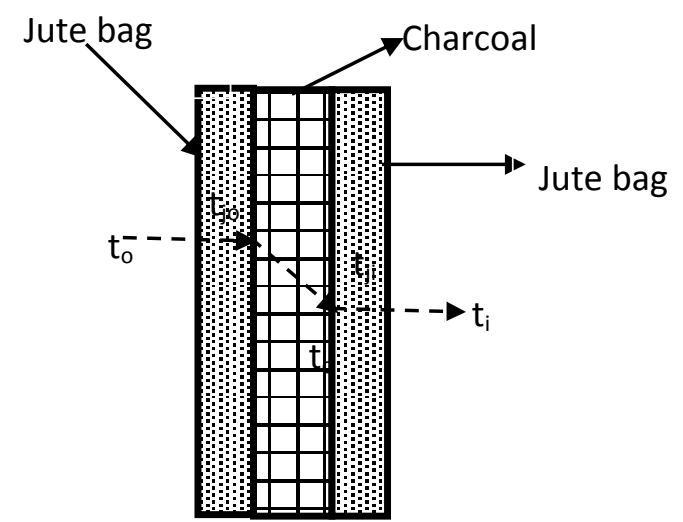

Figure 1: Temperature gradient across the side of the cabin

Table 1: Thickness and thermal resistance of insulating materials

\begin{tabular}{cccc}
\hline Materiawl & $\begin{array}{c}\text { Thickness } \\
(\mathrm{m})\end{array}$ & $\begin{array}{c}\text { Thermal } \\
\text { conductivity } \\
(\mathrm{W} / \mathrm{mK})\end{array}$ & $\begin{array}{c}\text { Resistance } \\
\left(\mathrm{M}^{2} \mathrm{~K} / \mathrm{W}\right)\end{array}$ \\
\hline Jute bag & 0.1 & 0.6 & 0.17 \\
Charcoal & 0.15 & 0.2 & 0.75 \\
\hline
\end{tabular}

Total thermal resistance was calculated as $1.26 \mathrm{~m}^{2} \mathrm{~K} / \mathrm{W}$. The average ambient temperature and expected temperaure inside the cabin measured with digital thermometer was $32.5^{\circ} \mathrm{C}$ and $20^{\circ} \mathrm{C}$ respectively. Total heat loss per unit area as calculated from equations(1-3) is $9.92 \mathrm{~W} / \mathrm{m}^{2}$. Temperature across jute bag and chacoal chamber were calculated using eqns.(4) and (5) respectively;

$$
Q_{l}=\frac{t_{o}-t_{j o}}{R_{j o}}
$$

$t_{j o}=30.81^{\circ} \mathrm{C}$

$$
\begin{aligned}
Q_{l} & =\frac{t_{j o}-t_{c}}{R_{c}} \\
t_{o} & =23.37^{\circ} \mathrm{C} .
\end{aligned}
$$

Heat transferred from outside to inside of storage cabin is calculated using equation (7).

$$
\begin{aligned}
\left(t_{o}-t_{j o}\right)+\left(t_{j o}\right. & \left.-t_{c}\right)+\left(t_{c}-t_{j i}\right)+\left(t_{j i}-t_{i}\right) \\
& =Q\left(\frac{X_{j o}}{K_{j o} A_{j o}}+\frac{X_{C}}{K_{C} A_{C}}+\frac{X_{j i}}{K_{j i} A_{j i}}\right)
\end{aligned}
$$

Therefore, substituting the values into equation (7), total heat flow into the cabin unit was calculated as $0.255 \mathrm{~kW}$. This amount of heat was considered in selection of suction fan powered by $24 \mathrm{~V}$ DC $0.37 \mathrm{~kW}$ motor. Furthermore, if $20 \%$ of the heat should be supplied exclusively, by the cooling water, while the rest is achieved through cooling air, we may re-write the heat transfer equation for cooling water according to eqn. (8) as follows:

$$
0.2 Q t=\frac{m}{C_{P} \Delta T}
$$


In (8), $\mathrm{m}$ is themass of water, $\mathrm{kg} \mathrm{C}_{\mathrm{p}}$ is the specific heat capacity of water $(4.18 \mathrm{~kJ} / \mathrm{kg})$; $\mathrm{t}$ is the time, $\mathrm{s}$; and $\Delta \mathrm{T}$ is the temperature difference, $\mathrm{K}$.

From Eqn. 8, it was determined that 3.5 litres of water should suffice for each hour of cooling storage. In practical terms, the quantity of water required will be much less due to condensation and re-circulation of water within the closed system. To calculate air flow rate required for temperature reduction in the cooling chamber, equation (9) was used and this was estimated as $61.2 \mathrm{~m}^{3} / \mathrm{hr}$.

$$
Q=\frac{C_{p} \rho V\left(t_{0}-t_{i}\right)}{3600}
$$

In (9) $Q$ is the heat flow into the storage cabin (kW); $t_{o, j o, c, j i, i}$ is the temperature at outside, outer jute, charcoal, inner jute, and inside cooler $\left({ }^{\circ} \mathrm{C}\right), A_{j o, c, j i}$ is the cross sectional areas of outer jute bag,charcoal and inner jute bag $\left(\mathrm{m}^{2}\right), C_{p}$ is the specific heat of air $\left(\mathrm{kJ} / \mathrm{kg}^{\circ} \mathrm{C}\right), \rho$ is the air density $\left(\mathrm{kg} / \mathrm{m}^{3}\right)$ and $V$ is the airflow rate $\left(\mathrm{m}^{3} / \mathrm{hr}\right)$

\subsubsection{Total Quantity of Produce to Be Stored}

Storage volume (V) was estimated from the volume of the structure given in eqn. (10)

$$
V=\text { length } \times \text { width } \times \text { height }
$$

This was calculated as $108,100 \mathrm{~cm}^{3}$. On the average, one $\mathrm{kg}$ of produce occupies $1162 \mathrm{~cm}^{3}$. Therefore, total estimated quantity that can be stored in the storage bin is $92 \mathrm{~kg}$.

\subsection{Description of the Evaporative Cooling Storage Bin}

The design of the evaporative cooler is based on the principle of evaporation which results in a cooling effect. The facility is an enclosed structure that allows air to pass through pad materials and a suction fan is centrally located to draw air into the storage structure. A water distribution system is used to drip water constantly into the composite pad materials. As the water drips into the pad materials, the suction fan draws in cool air into the storage chamber.During this process the warm air which has sensible heat passes through the wetted pad and is changed to latent heat due to the evaporation that occurs.

\subsection{Construction of the Storage Bin}

The evaporative storage bin is shown in Figure 2 while the orthographic view is shown in Figure 3. It is a modification of Dvizama [11] prototype design but has water reservoirlocated at the top of the storage bin. The cooler comprises of a cabin structure, composite pad material (Jute bag and charcoal), water distribution network and fan. The cabin was constructed with stainless steel, ply wood and wire gauze. The pad materials were filled in the hollow cavity between outer and inner wire gauze. The water distribution network was connected through the overhead water tank located at the top of storage bin.

\subsection{Performance Evaluation}

The perforance evaluation involved the no-load and the load tests. In the no-load test, the evaporative cooler was tested without putting any food material in it. The ambient temperature and the cooler temperature were recorded. The temperature reading was taken for 3 days between $10 \mathrm{am}$ and $4 \mathrm{pm}$ daily. On the first day, it was tested hourly for 6 hours but on the second and third days, readings were recorded in 30 minutes interval for 6 hours. During the load test, the stored product were kept inside the evaporative cooler and a control experiment kept at ambient air. The initial weight of each product was 500g.

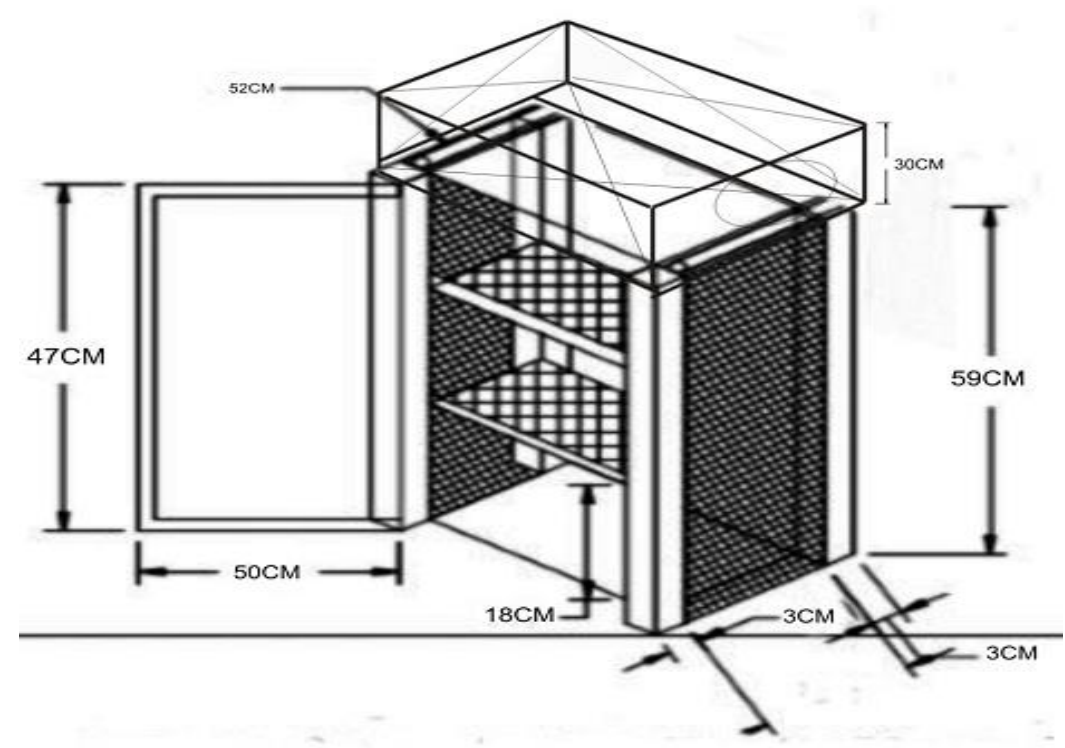

Figure 2: Isometrc view of the evaporative cooler 

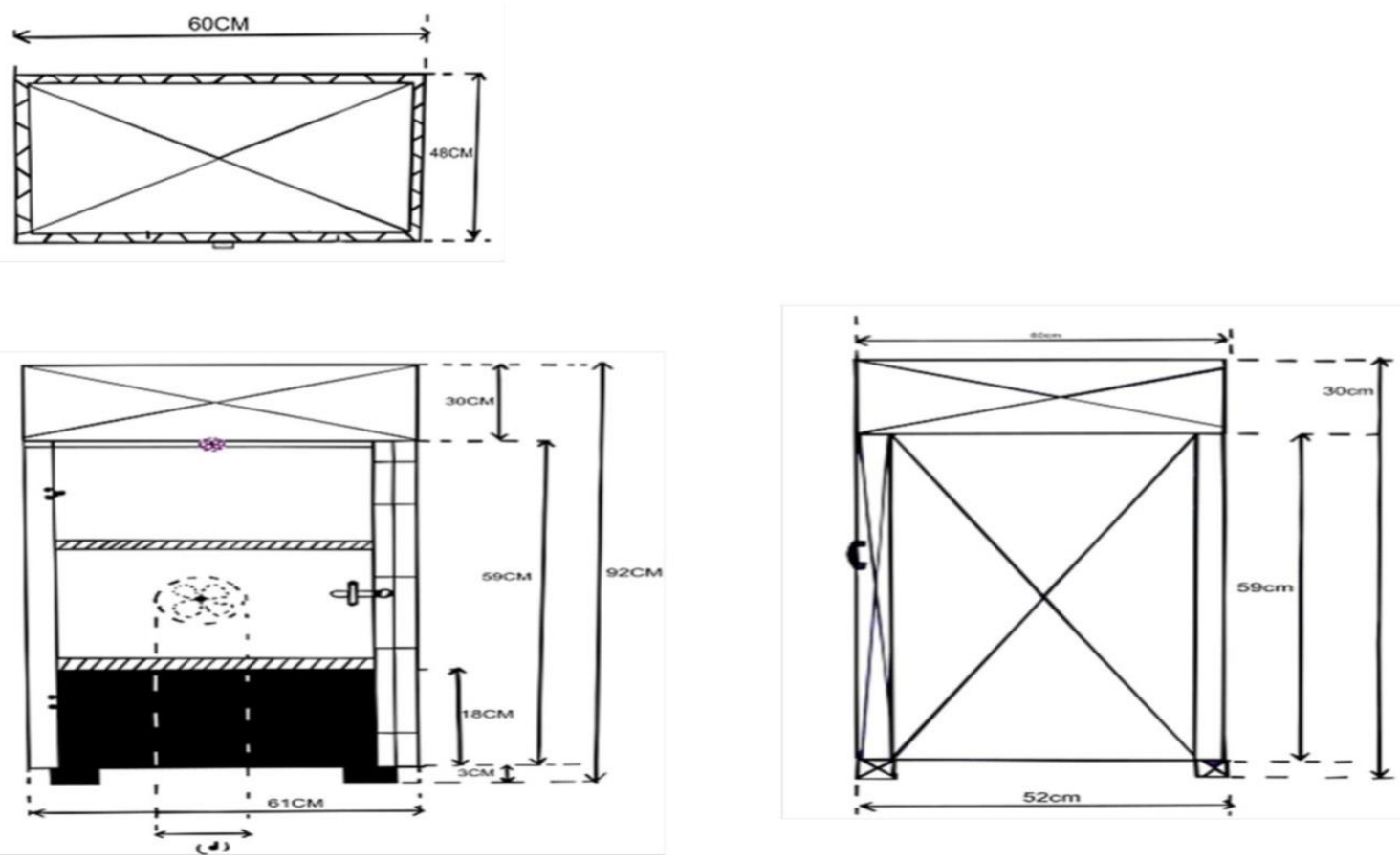

Figure 3: Orthographic view of the evaporative cooler

\section{RESULTS AND DISCUSSION}

\subsection{Performance Evaluation}

The evaporative cooler was used to store tomatoes, garden egg and carrot. The analysis was done in load and no- load tests. A total of 4 litres of water was used per day in the analysis.

\subsubsection{Results of the No load test}

The results of the experiment are given in Figures 4-6. Average air temperature and inner cooler temperatures were measured to be $32^{\circ} \mathrm{C}$ and $27^{\circ} \mathrm{C}$ respectively. Mean relative humidity inside the cooler is $58 \%$, thus from psychrometric chart, wet bulb temperature of the air is $21.5^{\circ} \mathrm{C}$. The saturation efficiency was calculated using equation (11)as $42 \%$ and this shows the ability of the device to evaporate water (cool) at a given relative humidity [6].

$$
S E=\frac{t_{0}-t_{i}}{t_{0}-t_{w b}} \times 100
$$

Where $t_{w b}$ is the wet bulb temperature of the air.

\subsubsection{Results of the Load Test of the Evaporative Cooler}

The results of the load test are presented in figs. 7 and 8.

\subsubsection{Colour Change}

The change in colour was more pronounced in the products kept at ambient conditions (Figure7). The colour of the tomatoesdid not change until it decayed on the seventh day. This was in agreement with results obtained by Zakari et al. [19]. Infact, Deoraj et al. [20] reported successful storage of tomatoes for 14 days in an evaporative cooler, which was better than conventional refrigerator. Colour of garden eggs changed from yellowish green to red. Carrot didnot have much change in colour but it started to spoil from the sixth day. It was found that colour changes occurred earlier on the produce kept at ambient conditions.

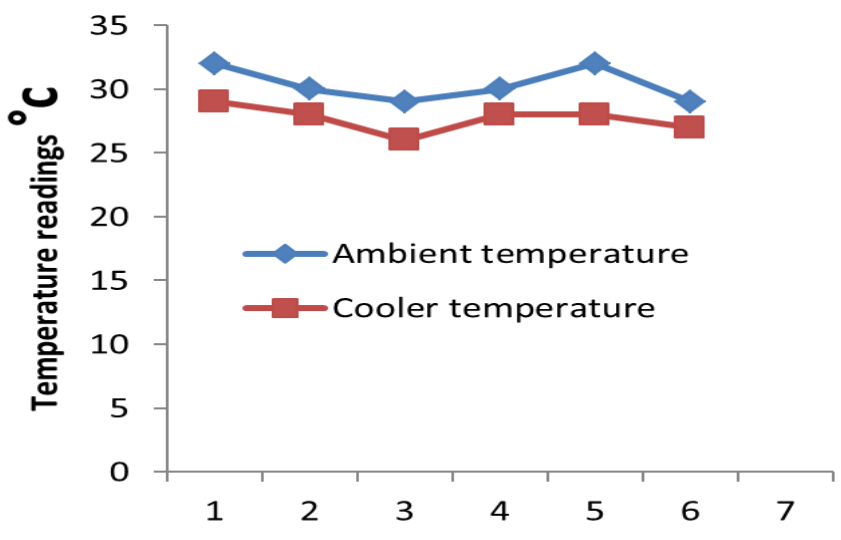

Experimental runs at intervals of 1 hour Figure 4: First day of no-load test

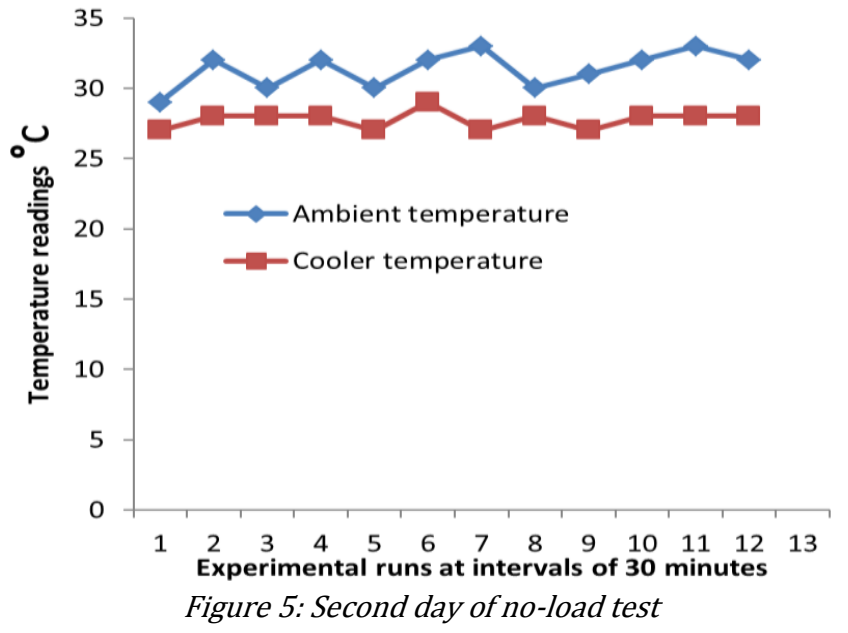



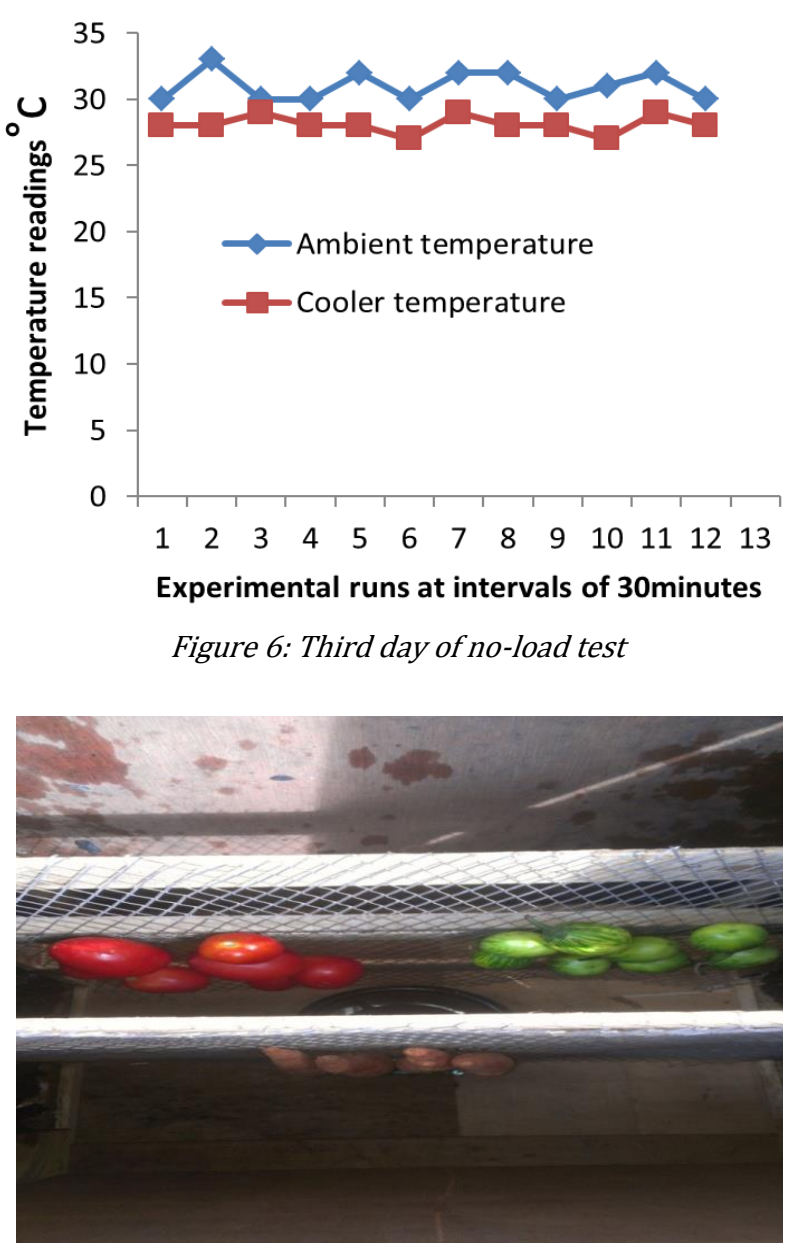

Figure 7: Storage chamber with produce

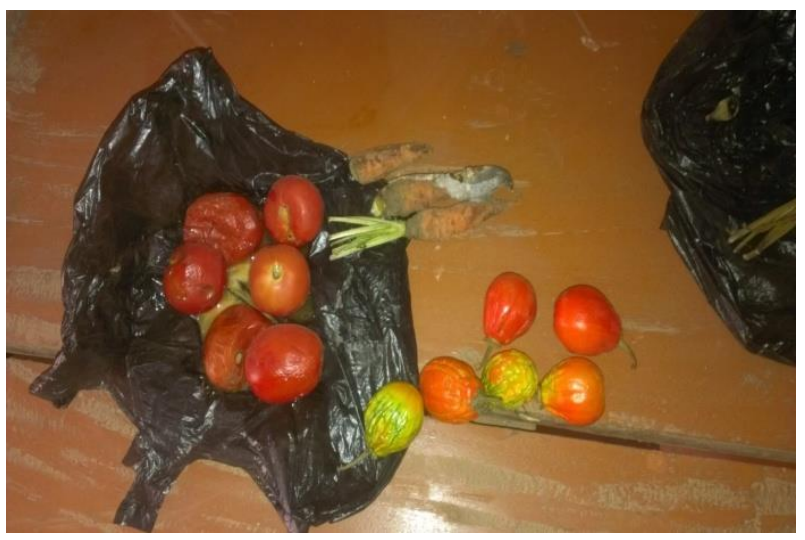

Figure 8: Control experiment

\subsubsection{Weight Loss}

The stored products were assessed and weighed after 3 days.Results were recorded and represented in Figure 9. These results are comparable with those reported by Mogaji and Fapetu [17], who observed a $12 \%$ loss in weight for carrots and $20 \%$ for tomatoes after 2 weeks.

\subsubsection{Firmness}

Firmness was determined by feeling. The change in the firmness was more pronounced in the carrot and tomatoes because of their shapes. The produce stored in the evaporative cooler retained their freshness longer than those stored at ambient conditions.

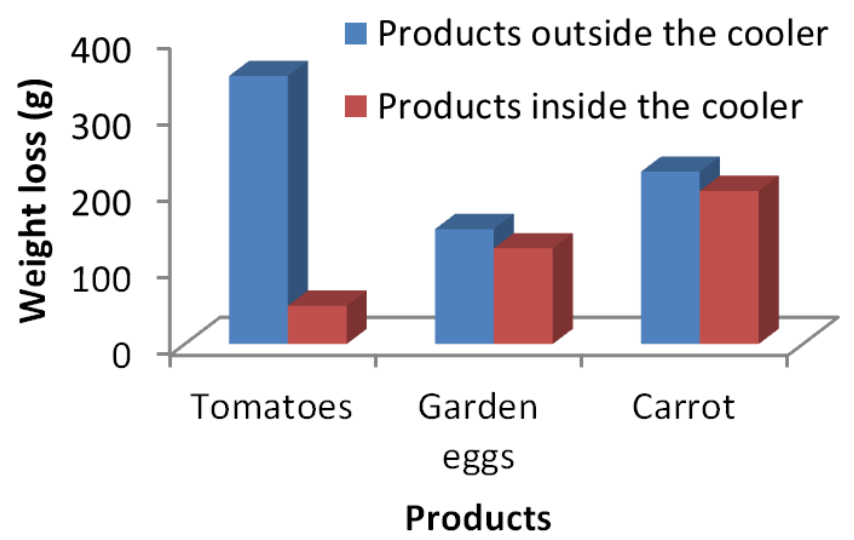

Figure 9: Weight loss for the three products

\section{CONCLUSION}

This study was carried out in order to provide an alternative storage facility for fruits and vegetables. Although the performance of the evaporative cooler facility fell slightly short of expectations, it canhowever be used to prolong the storage life of fruits and vegetables better than keeping the produce in ambient air conditions. Produce quality showsa delay in colour change and shrivelness when compared with produce kept at ambient conditions. The evaporative cooler can be used as a temporary means of storage for fruits and vegetables. Its use can help reduce postharvest losses and also generate more income for farmers.

\section{REFERENCES}

[1] Salunkhe, D. K., and Kadam, S. S. Handbook of Fruit Science and Technology, New York, 1995.

[2] UNIDO. Appropriate Industrial Technology for Food Storage Technology, No. 7. United Nations, New York, 1979.

[3] Ndirika, V. I. 0 and Asota, C. N. An Evaporative Cooling System for Rural Storage of Fresh Tomato. Journal of Agricultural Engineering and Technology, Vol. 2(4), pp 56-66. 1994,

[4] Sanni, L. A. Development of Evaporative Cooling Storage System for Vegetable Crops M.Sc. project report, Department of Agricultural Engineering, Obafemi Awolowo University, Ile-Ife, 1999.

[5] Barre, H. J., Sammet, L. L. and Nelson, G. L. Environmental and Functional Engineering of Agricultural Buildings, Van Nostrand Reinhold Company, New York, 1988.

[6] Mahmud M. A , Hossain M. A , Muktadir M. A. Design Optimization and Installation of the Evaporative Cooler in the Perspective of Bangladesh, International Journal of Emerging Technology and 
Advanced Engineering, Vol. 2 (11), , pp. 741749.Available online at www.ijetae.com 2012.

[7] Liberty J. T., Agidi G., and Okonkwo W. I. Predicting Storability of Fruits and Vegetables in passive evaporative cooling structures, International Journal of Scientific Engineering and Technology. Vol. 3, issue 5, pp. 518-523. 2014.

[8] NSPRI. Storage of Fruits and Vegetables. Nigerian Stored Product Research Institute Bulletin. 7, 1990.

[9] FAO. FAO production yearbook, vol. 34. FAO, Rome, 1983.

[10] Wiersma, F. Evaporative Cooling Inventilation of Agricultural Structures, An American Society of Agricultural Engineers Monograph 6th series, Michigan, USA, 1983.

[11] Dzivama, A. U. Performance Evaluation of an Active Cooling System for the Storage of fruits and Vegetables. Ph.D. Thesis, Department of Agricultural Engineering, University of Ibadan, Ibadan, 2000.

[12] Abdalla, K. N. and Abdalla, A. M. Utilization of Date Palm Leaves and Fibers as Wetted Pads in Evaporative Coolers, Agricultural Mechanization in Asia, Africa and Latin America Vol. 26 26(2), pp 5254. 1995.

[13] Sushmita, M. D., Hemant, D., and Radhacharan, V. Vegetables in Evaporative Cool Chamber and in Ambient, Macmillan Publ. Ltd.; London and Basingstoke, Pp 1 -10. 2008.

[14] Olosunde, W. A. Performance Evaluation of Absorbent Materials in the Evaporative Cooling
System for the Storage of Fruits and Vegetable. M.Sc. thesis, Department of Agricultural Engineering, University of Ibadan, Ibadan 2006.

[15] Mordi, J. I. and Olorunda, A. O. Effect of Evaporative Cooler Environment on the Visual Qualities and Storage Life of Fresh Tomatoes. J. Food Sci. Technol. 40(6), 587-591. 2003.

[16] Helmy, M. A., Eltawil, M. A., Abo-Shieshaa, R. R., Elzan, N. M. Enhancing the Evaporative Cooling Performance of Fan Pad System using Alternative Pad Material and Water Film over the Greenhouse Roof. CIGR JournalVol. 15 (2), pp 173-187. 2013.

[17] Mogaji, T. S. and Fapetu, O. P. Development of an Evaporative Cooling System for the Preservation of Fresh Vegetables. African Journal of Food Science, Vol. 5 (4), pp 255-266. 2011.

[18] Abbouda, S. K., and Almuhanna, E. A. Improvement of Evaporative Cooling System Efficiency in Greenhouses, International Journal of Latest Trends in Agriculture \& Food Sciences, Vol. 2 (2), pp.20495684. 2012.

[19] Zakari M. D, Y. S. Abubakar, Y. B. Muhammad, N. J. Shanono, N. M. Nasidi, M. S. Abubakar, A. I. Muhammad, I. Lawan and R. K. Ahmad Design and Construction of an Evaporative Cooling System for the Storage of Fresh Tomato. ARPN Journal of Engineering and Applied Sciences, Vol. 11, No. 4, pp: 2340-2348. 2016.

[20] Deoraj, S, Ekwue, E. I. and Birch, R. An Evaporative Cooler for the Storage of Fresh Fruits and Vegetables. The West Indian Journal of Engineering Vol.38, No.1, July pp.86-95. 2015. 